\title{
HOME AWAY FROM HOME - THE ROLE OF SOCIAL SUPPORT FOR INTERNATIONAL STUDENTS' ADJUSTMENT
}

\author{
'Sana Anwar Lashari, Amrita Kaur \& Rosna Awang-Hashim \\ School of Education and Modern Languages, \\ Universiti Utara Malaysia, Malaysia
}

${ }^{1}$ Corresponding author: sanalasharisana@gmail.com

Received: 2 June 2018 Revised: 13 November 2018 Accepted: 21 November 2018

\begin{abstract}
Purpose - Academic and psychological adjustment of international students is central to their success while pursuing their degrees abroad. However, acculturation stress is abundant and may pose as a challenge. Thus, in this study we examined whether social support mediates the association between acculturation stress and academic and psychological adjustment.

Methodology - A cross sectional research design was employed. A total of 200 postgraduate international students from three Malaysian public universities were recruited to participate in the study. The Student Adjustment to College Questionnaire was employed to measure their academic adjustment and psychological adjustment. The Multidimensional Scale for Perceived Social Support and the Acculturative Stress Scale for International Students were used to collect data on social support and acculturation stress. Path analysis by AMOS 23 was used to test the hypothesized relationship.
\end{abstract}

Findings -Results provided support for the proposed model, revealing that social support was associated with greater academic and psychological adjustment among international students.

Significance - The present study has implications for university policies, counsellors, and student affairs departments on the need to take measures to facilitate healthy academic and psychological adjustment among international students. 
Keywords: International students, higher education, acculturation stress, social support, academic adjustment and psychological adjustment.

\section{INTRODUCTION}

Millions of students travel every year to pursue higher education. These international students contribute to cultural diversity on university campuses, and as they bring with them a wide range of knowledge and skills, they also add to the intellectual capital of the host country. Their stay is mutually beneficial as they bring various assets to the host country and in return gain higher education (Smith $\&$ Khawaja, 2011). However, the socio-psychological and academic adjustment of international students may not be easy, as they try to adapt to differences in cultural and academic environment between them and the host country (Glass \& Westmont, 2014). International students frequently report that factors such as language barriers (Meng, Zhu, \& Cao, 2018), academic styles (Misra, McKean, West, \& Russo, 2000), separation from home (Hendrickson, Rosen, $\&$ Aune, 2011), poor social integration and problems in daily life tasks (Yeh \& Inose, 2003) inhibit their adjustment. These factors also contribute towards stress and anxiety, which impact upon international students' acculturation (Meng et al., 2018; Yan, 2017), i.e., their ability to respond to or cope with life events that are rooted in cross-cultural contact (Berry, Phinney, Sam, \& Vedder, 2006). Furthermore, failure to adjust to these challenges can be detrimental to various aspects of college life, resulting in poor academic results, psychological and physical health issues and dropping out (Hang, Kaur, \& Nur, 2017; Martirosyan, Hwang, \& Wanjohi, 2015).

Recent studies have found mixed results on whether acculturation stress and academic and psychological adjustment challenges are beneficial or deleterious. A growing body of literature suggests that stressful life events can lead to stress related growth, i.e., positive life changes such as enhancing personal strength, discovering new possibilities in life, strengthening meaningful relationships, gaining an appreciation of life, and enhancing spiritual growth (Holm-Hadulla \& Koutsoukou-Argyraki, 2015; Kim \& Kim, 2013; Kim, Suh, \& Heo, 2014; Pogrebtsova, Craig, Chris, O'shea, \& González $\square$ Morales, 2018). On the other hand, it has also been demonstrated that international students encounter cultural identity 
confusion (de Araujo, 2011), strained interpersonal relationships (Glass, 2014), health problems (Li et al., 2017), feelings of isolation (Wang \& Hannes, 2014), homesickness (Poyrazli \& Grahame, 2007), and poor self-esteem (Kim \& Kim, 2013) which in return affect their psychological well-being. Additionally, students who experience psychological problems face a greater risk of poor academic performance, which in turn perpetuates a cycle of stress, thus increasing academic failure and the potential to drop out (Richardson, Abraham, \& Bond, 2012).

International students may also experience problems in academic adjustment due to an unfamiliar education system (Poyrazli \& Grahame, 2007). A variety of factors associated with this element contribute significantly to academic stress. For example, international students experience problems due to differences in study and test taking techniques, classroom instruction and grading styles of the host country (Poyrazli \& Grahame, 2007). Other challenges related to academic adjustment include student-supervisor relationship and quality of interactions with faculty (Cruwys, Greenaway, \& Haslam, 2015) and new teaching styles. Some students have reported difficulties in meeting deadlines, working with other students in teams from different cultures (Wan, Nordin, \& Razali, 2013), fulfilling course requirements, time management, and the pressure of doing well academically (Lowinger, He, Lin, \& Chang, 2014).

In order to deal with acculturation stress and its accompanying stressors, an individual needs to use positive coping mechanisms (Dunkel-Schetter, Folkman, \& Lazarus, 1987; Lee \& Ciftci, 2014). Social support has been found to be a significant way of dealing with academic and psychological stress (Adelman, 1988; Rui \& Wang, 2015; Van Gorp, Boroş, Bracke, \& Stevens, 2017). Social support refers to the level of support that an individual perceives from general or specific supportive behaviours of people in their network such as friends or peer groups, which enhances functioning or may buffer him or her from adverse outcomes (Dao, Donghyuck, \& Chang, 2007). There are many sources of social support including academic peer groups (Dao et al., 2007), informal interactions with faculty, personal tutorials (Rienties et al., 2012), social networks (Wilcox, Winn \& Fyvie $\square$ Gauld, 2005), student support services (Poyrazli \& Lopez, 2007), and intimate relationships with close friends and family (Myers-Walls et al., 2011). They provide individuals with the resources tocope with stress. Forexample, behaviours such as listening 
and demonstrating warmth and empathy support an individual's affective well-being (Wei et al., 2011) and facilitate international students' academic, behavioural and emotional adjustments (Zhou, Jindal-Snape, Topping, \& Todman, 2008). Hence, support sources help to reduce stress and assist international students in their psychological adaptation (Brisset, Safdar, Lewis, \& Sabatier, 2010; Sümer, Poyrazli, \& Grahame, 2007), increase self-esteem (Sawir et al. 2008), and enhance academic performance (Rienties et al., 2012). Without addressing their stressors, international students may eventually develop physiological, emotional and psychological health issues (Hamamura \& Laird, 2014) that would affect their learning, engagement (Suárez-Orozco, Onaga, \& de Lardemelle, 2010), confidence (Zajacova, Lynch, \& Espenshade, 2005), academic and social competence (Duru \& Poyrazli, 2007) and self-concept in a negative manner (Heine \& Lehman, 2004).

International students typically enrol in native English speaking countries such as the United Kingdom, Australia, Canada, and the USA. However, the trend has shifted towards enrolling in non-native English speaking countries such as China, Malaysia, India, Japan, Singapore, South Korea, and Taiwan (Luo, 2017). Malaysia particularly has been successful in attracting a large group of international students by offering low tuition fees and quality education (Ahmad \& Buchanan, 2017). At present there are 122,000 international students from more than 160 countries in Malaysia (StudyMalaysia, 2017). Nevertheless, the difference between the students' personal expectations and the reality of their Malaysian experience renders them highly prone to the deleterious effects of acculturative stress, which can influence their academic adjustment and psychological wellbeing (Lowinger et al., 2014; Martirosyan, Hwang, \& Wanjohi, 2015). Several factors have been reported to contribute towards stress among international students in Malaysia. One example is the difficulty in understanding lecturers' accents due to local dialectal variation and slang, as a range of accents exist in Malaysia due to its multi-ethnic population (Wan et al., 2013). Accumulation of such challenges can cast a negative impact on international students' academic adjustment (Lillyman \& Bennett, 2014; Lu, Dear, Johnston, Wootton, \& Titov, 2014; Pan, 2015; Wider, Mustapha, Halik, \& Bahari, 2017). Social support is an indicative buffering factor to cope with the deleterious effect of acculturative stress as it lowers susceptibility to psychological illness (Finch \& Vega, 2003), which in turns enhances adjustment (Lee, Koeske, \& Sales, 2004; Olivas \& Li, 2006). 
Social support is as an important construct which has been examined in mediational relation with acculturation stress (Katsiaficas, Suárez-Orozco, Sirin, \& Gupta, 2013; Misra, Crist, \& Burant, 2003; Oppedal, Røysamb, \& Sam, 2004) and academic and psychological adjustment (Li \& Gasser, 2005; Zhou, Jindal-Snape, Topping, \& Todman, 2008). While there is rich literature describing acculturation stress affecting academic and psychological adjustment among international students, it can be noted that most of these studies are generally restricted to traditional study destinations such as the United Kingdom and Australia (Wan et al., 2013). To date, very few studies have been conducted in a multicultural and rapidly growing higher education hub such as Malaysia.

With the increasing diversity of international students, a study of this nature is essential for the advancement of knowledge in the field, as well as for Malaysia as the country aspires to recruit 250,000 international students in higher education (Kaur, Noman, \& Nordin, 2017). The study is also important for the development of student perspectives on related concepts, which will enable counsellors to formulate stress interventions that can be applied empirically to different cultures.

\section{Theoretical Framework}

Studies on acculturation stress and international students' adjustment have mainly applied instrumental theory, i.e., stress and coping theory (SCT) which explains how individuals adapt and cope in a culturally unfamiliar environment (Smith \& Khawaja, 2011; Zhou, Jindal-Snape, Topping, \& Todman, 2008). According to SCT, psychological stress is defined as "a particular relationship between the person and the environment that is appraised by the person as exceeding his or her resources and endangering his or her wellbeing" (Lazarus \& Folkman, 1984, p. 19). SCT states that in a new environment, individuals are faced with challenges. To overcome these challenges, they use certain ways known as the coping process to manage difficulties. SCT identifies social support as a key coping process in a new environment (Lazarus \& Folkman, 1984). The framework of the current study incorporates this theory and hypothesizes that international students using social support would engage in social interaction and build networks. This in turn would facilitate their academic and psychological adjustment. 
According to Hayes (2009) when a third variable plays an important role in governing the relationship between two other variables, this type of relationship is known as mediation. The present study considered social support as a mediator based on the following conditions provided by Hayes (2009):

(a) The predictor (acculturation stress) and outcome (academic and psychological adjustment) variables initially have a significant relationship (Yeh \& Inose, 2003),

(b) The potential mediator (social support) is significantly related with the predictor (acculturation stress) variable (Lee, Koeske, $\&$ Sales, 2004),

(c) The potential mediator (social support) is significantly related with the outcome (academic and psychological adjustment) variable (Andrade, 2006).

\section{METHODOLOGY}

\section{Research design}

The present study utilised a cross sectional research design for objective analysis of results and due to reliance on probability theory to test the statistical hypothesis (Popper, 2005).

\section{Participants}

The participants were 200 international students (45\% female and $55 \%$ male) with a mean age of 30 years $(\mathrm{SD}=7.07$, range $22-45$ years) who were recruited from three Malaysian public universities.

\section{Procedure}

Institutional permission to collect the data was obtained from each university. The cover letter attached to the questionnaire provided details about the purpose of the study, and the universities concerned were assured that individual responses and the names of the institutions would not be revealed in any publication. Students signed a consent form which informed that their participation was voluntary. The self-reported questionnaire, which took 15-20 minutes to complete, was administered in the English language. 


\section{Measures}

The instruments used in the study were piloted to establish reliability and validity prior to data collection.

\section{Demographic Questionnaire}

A demographic questionnaire was used to collect participants' background information such as age, gender, the level of education, semester and nationality.

\section{Student Adaptation to College Questionnaire}

Students' psychological and academic adjustments were measured by the Student Adaptation to College Questionnaire (Baker \& Siryk, 1989). The questionnaire has been validated by various studies in several countries including Belgium (Meng et al., 2018) and the United States (Glass, Gómez, \& Urzua, 2014; Credé \& Niehorster, 2012). It consists of four subscales: academic adaptation, social adaptation, personal-emotional adaptation, and attachment. However, in the present study only the academic and psychological adaptation scales was used due to the study focus. Academic adjustment was measured using 18 items (e.g., "I attend classes regularly and I consider a university degree important."), while psychological adjustment was measured using 9 items, (e.g., "I am not able to control emotions well and I get angry too easily."). All items were rated on a 5-point Likert scale, ranging from $1=$ strongly disagree to $5=$ strongly agree. Good internal consistency was obtained for both academic adjustment $(\alpha=77)$ and psychological adjustment $(\alpha=$ $.85)$.

\section{Social Support}

Social support was measured using the Multidimensional Scale for Perceived Social Support (MSPSS) (Zimet, Dahlem, Zimet, \& Farley, 1988), which comprises 12 items designed to assess perceptions of social support from three specific sources: family, friends, and significant others. However, in the present study only the items related to support from friends were used as peers are instrumental in proving emotional and informational support to students who are away from home. Moreover, they are immediately available on campus and have information relevant to negotiating the university environment (Crockett et al., 2007; Rodriguez, Mira, Myers, Morris, \& Cardoza, 2003). Additionally, peer support is 
associated with better adjustment (Schneider \& Ward, 2003) and lower psychological distress (Rodriguez et al., 2003). Items were also rated on a 5-point Likert scale (e.g., "My friends really try to help me."), with higher scores indicating greater levels of perceived social support. The scale has also been validated by previous studies (Canty-Mitchell \& Zimet, 2000; Friedlander, Reid, Shupak, \& Cribbie, 2007; Zimet et al., 1988) and good internal consistency ( $\alpha$ $=.71$ ) was obtained in the present study.

\section{Acculturation Stress}

Acculturation was measured using 36 items from the Acculturative Stress Scale for International Students (ASSIS) (Sandhu \& Asrabadi, 1994). The items on the scales are rated on a 5-point Likert scale ranging from 1 (strongly disagree) to 5 (strongly agree) where higher score indicate high acculturation stress. A sample item is "People from some ethnic groups show hatred toward me nonverbally." In the present study the Cronbach's alpha value was 0.84. Previous studies showed higher internal consistency (Duru \& Poyrazli, 2007; Lowinger et al., 2014; Yeh \& Inose, 2003).

\section{Statistical Analyses}

To test the adequacy of the proposed model, this study employed Path analysis using AMOS 23 (Bentler \& Wu, 2005). Models of the study were tested with the standardised coefficients obtained by maximum likelihood estimation. Besides chi-square test statistics, goodness of fit of every path model was evaluated from multiple fit indices (Bentler, 2007) such as comparative fit index (CFI), the root mean squared residual (RMSEA), and the standardized root-meansquare test (SRMR) since the chi square test is sensitive to sample size (Bergh, 2015). For CFI, a value greater than .90 indicates a good fit; superior to .95 being ideal. For SRMR and RMSEA, a value below .05 indicates a good fit, whereas values up to .08 represent acceptable errors of approximation (Bentler, 2007).

\section{RESULTS}

\section{Preliminary Analysis}

Prior to running the hypothesized models, the final sample size $(\mathrm{n}=$ 200) was determined after dealing with the missing data. The amount of missing data in our sample was small: $1.3 \%$ of values across all 
scales (Tabachnick \& Fidell, 2007). To address the missing value, we removed participants $(\mathrm{n}=31)$ as the participants missed more than $30 \%$ of the scales, whereas we used item-mean substitution (IMS) to impute the remaining missing values. Previous studies found that if the missing data is less than $10 \%$, IMS reproduces dataset as accurately as other imputation methods (e.g., multiple imputation) across various missing patterns (Bono, Ried, Kimberlin, \& Vogel, 2007; Zhang \& Goodson, 2011). No multivariate outliers were found. Univariate normality with skewness and kurtosis for all the variables ranged between -1 and 1 .

\section{Testing the Proposed Model}

To determine the model adequacy, we tested three models (a) direct effect, including direct path between acculturation stress with academic and psychological adjustment, (b) partial mediation path, indirect path between social support and academic and psychological adjustment, and (c) full-mediation path, including both direct and indirect mediation paths (Preacher \& Hayes, 2004).

To test the mediating effects of social support on the relationships between acculturation stress and academic and psychological adjustment, bias-corrected $95 \%$ confidence intervals were computed.

\section{Results}

Model 1 showed a good fit to the data, $\chi^{2}(1)=2.49$, CFI $=.96$, $\mathrm{RMSEA}=.08, \mathrm{SRMR}=.01$. The standardized coefficient showed that acculturation stress negatively and significantly related to academic adjustment $(\beta=-.42 p<.001)$, and psychological adjustment $(\beta=-.16$, $\mathrm{p}<.001)$. Altogether, the predictor explained $17 \%$ of the variance of academic adjustment, and $8 \%$ of psychological adjustment.

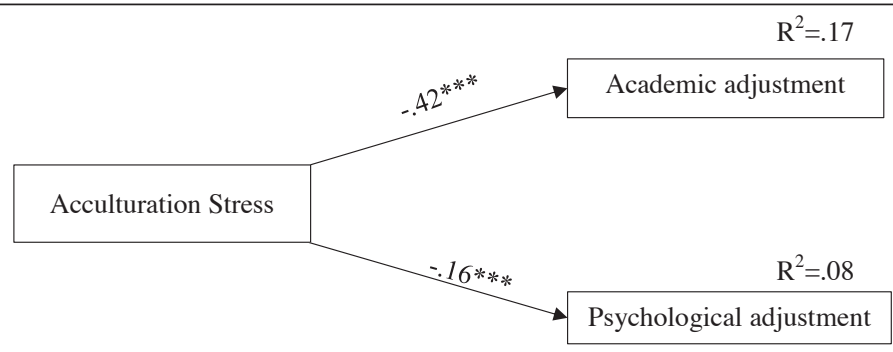

Figure 1. Graphic portrayal of the hypothesized Model 1. All standardized coefficients reported are significant at $\mathrm{p}<.01$. 
Subsequently, we tested Model 2 (see Figure 2, dashed lines) specifying acculturation stress as an indirect predictor of the outcome, with this relation being mediated by social support. The indirect paths are represented by dashed lines in Figure 2; the standardized regression values correspond to the first values represented on the top of each path. Model 2 yielded unsatisfactory fit to the data $\chi^{2}(3)$ $=31.90 ; \mathrm{CFI}=.81 ; \mathrm{RMSEA}=.22 ; \mathrm{SRMR}=.01$. Acculturation stress was negatively related to social support $(\beta=.-64, p<.001)$ which, in turn, was positively related to academic adjustment $(\beta=.21, \mathrm{p}$ $<.001)$ and psychological adjustment $(\beta=.28, \mathrm{p}<.001)$. Altogether, the predictor explained $4 \%$ of the variance of academic adjustment, and $8 \%$ of psychological adjustment.

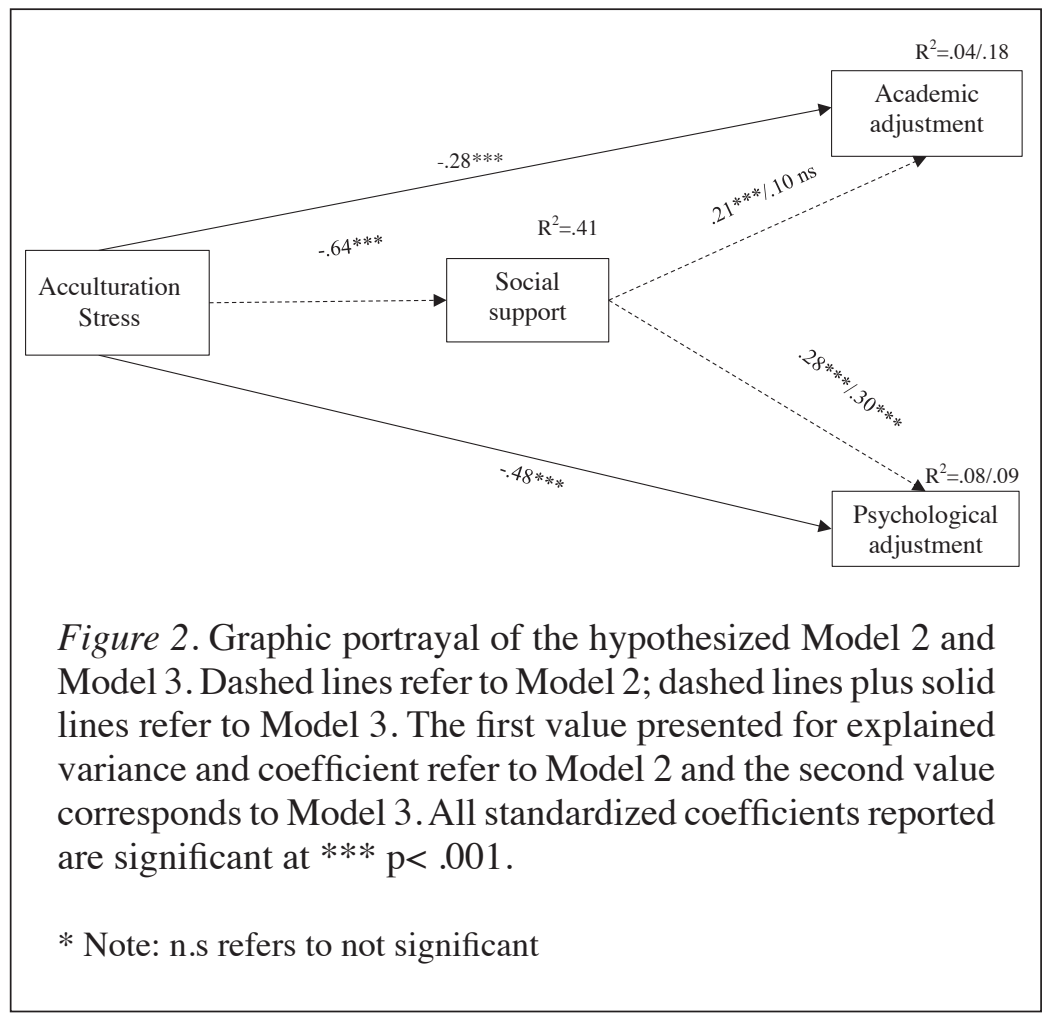

In the final analysis, we tested the full mediation model, which is where direct and indirect effects were computed together in Model $3 \chi^{2}(1)=1.83$; SRMR=.008; CFI=.99; RMSEA=.06; adding direct paths significantly improved the model fit, $\Delta \chi^{2}(2)=30.07$. Acculturation stress was negatively related to social support $(\beta=.-64$, $\mathrm{p}<.001)$. The relationship between social support and psychological 
adjustment was found to be significant $(\beta=.30, \mathrm{p}<.001)$. However, the relationship between social support and academic adjustment was not significant $(\beta=.10)$. Altogether, the predictor explained $18 \%$ of the variance for academic adjustment, and $9 \%$ for psychological adjustment. Model 3 yielded a significantly higher fit than Model 2. Additionally, the results show that adding a direct path to the model increased the explained variance of academic adjustment to $18 \%$ and psychological adjustment to $9 \%$. However, after controlling for social support the relationship between acculturation stress and academic adjustment became non-significant, while all the rest of the hypothesized path coefficients remained significant. Thus, in terms of parsimony, the fully mediated model offered the best-fitting solution.

Despite the findings, the cross-sectional nature of the data made it difficult to assert the directionality of the association found. To overcome this limitation, we specified an alternative model (Model 4) in which we reversed the direction of the effects between the predictor and the criterion variables (Cordeiro, Paixão, Lens, Lacante, \& Luyckx, 2018). Model 4 included paths from academic and psychological adjustment to acculturation stress via social support. Model 4 yielded a poor fit to the data, $\chi^{2}(3)=30.21$; $\mathrm{CFI}=.82$; $\mathrm{RMSEA}=.21$; $\mathrm{SRMR}=.01$, thus providing some support for the casual ordering proposed in Model 3.

Table 1

Goodness-of-Fit Index for the Hypothesized Models

\begin{tabular}{llllllll}
\hline Model & $\chi^{2}$ & df & $\chi^{2} / \mathrm{df}$ & $\mathrm{N}$ & CFI & RMSEA & SRMR \\
\hline Model 1 & 2.49 & 1 & 2.49 & 200 & .96 & .08 & .01 \\
Model 2 & 31.90 & 3 & 10.63 & 200 & .81 & .22 & .01 \\
Model 3 & 1.83 & 1 & 1.83 & 200 & .99 & .06 & .008 \\
Model 4 & 30.21 & 3 & 10.07 & 200 & .82 & .21 & .01 \\
Model comparisons: & $\Delta \chi^{2}$ & $\Delta$ & & & & & \\
Model 2 vs. Model 1 & 29.41 & 2 & & & & & \\
Model 2 vs. Model 3 & 30.07 & 2 & & & & & \\
\hline
\end{tabular}

Taken together, the results on Model 3 support the mediation hypothesis outlined. 


\section{Discussion}

The present study proposed that social support mediates the relationship between acculturation stress and academic adjustment and psychological adjustment. To test the hypothesized model, we proposed three models. Model 3 had significantly better fit compared with Models 1 and 2. The results of the study indicate that a high level of stress has a negative impact on individual psychological adjustment. These results are consistent with previous studies which found that international students face more psychological symptoms due to high levels of stress, as it causes anxiety (Sam, Tetteh, \& Amponsah, 2015), homesickness (Thomas \& Sumathi, 2016) and low self-esteem (Liao \& Wei, 2014) which in turn affect their academic adjustment and psychological adjustment.

The final model highlights a significant negative relationship between acculturation stress and social support, which positively predicted psychological adjustment. In the current study context, these findings are interpreted with an explanation that international students lose contact with their loved ones and face loneliness, which causes emotional distress and psychological maladjustment (Naeeni et al., 2015). It is understood that social support from interpersonal networks, the graduate program itself, or the campus international student office have the potential to facilitate students in their psychological adjustment by reducing stress through proper social support (Ellison, Steinfield, \& Lampe, 2007; Yeh \& Inose, 2003 ; Zhang \& Goodson, 2011).

The study also revealed that a negative relationship between acculturation stress and social support did not predict academic adjustment. However, contrasting results have been found in previous studies which have shown that social support networks such as peers and faculty staff helped international students to adjust well academically (e.g., Ellison et al., 2007; Zhang \& Goodson, 2011). These findings suggest that students who have established social relationships would experience low levels of acculturation stress (Andrade, 2006; Singh, Zain, \& Jamil, 2011) and would find it less challenging to cope with new academic demands; hence they would perform better academically. However, it has also been suggested that some forms of social support and activities such as participation in social club activities can have a negative effect on the academic performance of international students (Sennett, Finchilescu, Gibson, 
\& Strauss, 2003) and may not contribute signficantly to academic adjustment. Hence, social support seems to be more instrumental in positively affecting their psychological adjustment compared with academic adjustment (Smith \& Khawaja, 2011).

This study provides an understanding of international students' adjustment-related challenges. By revealing the mediating role of social support in the link between acculturation stress and academic and psychological adjustment, the study has contributed valuable insights into what constitutes an effective environment for international students' adjustment and more importantly, how social support acts upon psychological adjustment. The results of the study offer useful guidelines to institutions that wish to enhance student adjustment and attract more international students.

Based on the results, we provide some practical suggestions on facilitating the adjustment process of international students. Institutions of higher learning should provide numerous social support structures and introduction activities that provide information regarding the educational culture of the institution. Specifically, they should provide culturally sensitive training to learn about the host culture in terms of communication patterns, conflict resolution, rules and conventions. Such training sessions would help international students to gain more knowledge of the local culture and help them feel more confident, which should lead to more effective communication and less emotional stress due to misunderstanding. Hence, their adjustment process would be enhanced. Social events and social networks that aim to bring national and international students together could also facilitate social support. Moreover, universities should provide adequate platforms to facilitate efforts by international students to establish organizations that would them become settled. They should also endeavour to actively provide programs and events through which international students can interact with each other to increase their social support network.

\section{Limitations and Implications for Future Studies}

The present study has some limitations. First, the data was collected at one point only, so longitudinal relations were not addressed. In order words, causal directions could not be determined as the research design was cross sectional. Future studies may adopt pretest and post-test methodology to determine whether the psychological 
symptoms of international students are pre-existing issues or outcomes of the acculturation. Second, the sample size was small, which may not have accurately reflected a comprehensive view of international students. Future studies using a larger sample size and longitudinal designs should be attempted. Third, the present study did not incorporate certain acculturation stressors (e.g., financial concerns). The effects of such stressors on students' adjustment are still under-researched. The present study also recommends that future research should explore various factors related to social involvement at the university and its effect on students' adjustment.

\section{References}

Adelman, M. B. (1988). Cross-cultural adjustment: A theoretical perspective on social support. International Journal of Intercultural Relations, 12(3), 183-204.

Ahmad, S. Z., \& Buchanan, F. R. (2017). Motivation factors in students decision to study at international branch campuses in Malaysia. Studies in Higher Education, 42(4), 651-668.

Andrade, M. S. (2006). International students in Englishspeaking universities: Adjustment factors. Journal of Research in International Education, 5(2), 131-154. https://doi. org/10.1177/1475240906065589

Baker, R. W., \& Siryk, B. (1989). Student adaptation to college questionnaire (SACQ). Los Angeles, CA: Western Psychological Services.

Bentler, P. M. (2007). On tests and indices for evaluating structural models. Personality and Individual Differences, 42(5), 825829.

Bentler, P. M., \& Wu, E. (2005). EQS 6.1 for Windows. Encino, CA: Multivariate Software. Inc.

Bergh, D. (2015). Chi-Squared Test of Fit and Sample Size-A Comparison between a Random Sample Approach and a Chi-Square Value Adjustment Method. Journal of Applied Measurement, 16(2), 204-217.

Berry, J. W., Phinney, J. S., Sam, D. L., \& Vedder, P. (2006). Immigrant youth: Acculturation, identity, and adaptation. Applied Psychology, 55(3), 303-332.

Bono, C., Ried, L. D., Kimberlin, C., \& Vogel, B. (2007). Missing data on the Center for Epidemiologic Studies Depression Scale: A comparison of 4 imputation techniques. Research in Social and Administrative Pharmacy, 3(1), 1-27. 
Brisset, C., Safdar, S., Lewis, J. R., \& Sabatier, C. (2010). Psychological and sociocultural adaptation of university students in France: The case of Vietnamese international students. International Journal of Intercultural Relations, 34(4), 413-426.

Canty-Mitchell, J., \& Zimet, G. D. (2000). Psychometric properties of the Multidimensional Scale of Perceived Social Support in urban adolescents. American Journal of Community Psychology, 28(3), 391-400.

Cao, C., \& Meng, Q. (2017). Mapping the Paths from Language Proficiency to Adaptation for Chinese Students in a NonEnglish Speaking Country: An Integrative Model of Mediation. Current Psychology, 1-12.

Cordeiro, P. M. G., Paixão, M. P., Lens, W., Lacante, M., \& Luyckx, K. (2018). Parenting styles, identity development, and adjustment in career transitions: The mediating role of psychological needs. Journal of Career Development, 45(1), 83-97.

Credé, M., \& Niehorster, S. (2012). Adjustment to college as measured by the Student Adaptation to College Questionnaire: A quantitative review of its structure and relationships with correlates and consequences. Educational Psychology Review, 24(1), 133-165.

Crockett, L. J., Iturbide, M. I., Torres Stone, R. A., McGinley, M., Raffaelli, M., \& Carlo, G. (2007). Acculturative stress, social support, and coping: Relations to psychological adjustment among Mexican American college students. Cultural Diversity and Ethnic Minority Psychology, 13(4), 347-355.

Cruwys, T., Greenaway, K. H., \& Haslam, S. A. (2015). The stress of passing through an educational bottleneck: A longitudinal study of psychology honours students.Australian Psychologist, 50(5), 372-381.

Dao, T. K., Donghyuck, L., \& Chang, H. L. (2007). Acculturation level, perceived English fluency, perceived social support level, and depression among Taiwanese international students. College Student Journal, 41(2), 287-296.

De Araujo,A. A. (2011). Adjustment Issues of International Students Enrolled in American Colleges and Universities : A Review of the Literature. Higher Education Studies, 1(1), 2-9. https:// doi.org/10.5539/hes.v1n1p2

Dunkel-Schetter, C., Folkman, S., \& Lazarus, R. S. (1987). Correlates of social support receipt. Journal of Personality and Social Psychology, 53(1), 71-80. 
Duru, E., \& Poyrazli, S. (2007). Personality dimensions, psychosocial-demographic variables, and English language competency in predicting level of acculturative stress among Turkish international students. International Journal of Stress Management, 14(1), 99-110.

Ellison, N. B., Steinfield, C., \& Lampe, C. (2007). The benefits of Facebook "friends:" Social capital and college students' use of online social network sites. Journal of Computer-Mediated Communication, 12(4), 1143-1168.

Finch, B. K., \& Vega, W. A. (2003). Acculturation stress, social support, and self-rated health among Latinos in California. Journal of Immigrant Health, 5(3), 109-117.

Friedlander, L. J., Reid, G. J., Shupak, N., \& Cribbie, R. (2007). Social support, self-esteem, and stress as predictors of adjustment to university among first-year undergraduates. Journal of College Student Development, 48(3), 259-274.

Glass, C. R. (2014). International student adjustment to college: Social networks, acculturation, and leisure. Journal of Park and Recreation Administration, 32(1), 7-25.

Glass, C.R., Gómez,E., \& Urzua, A. (2014). Recreation, intercultural friendship, and international students' adaptation to college by region of origin. International Journal of Intercultural Relations, 42, 104-117.

Glass, C. R., \& Westmont, C. M. (2014). Comparative effects of belongingness on the academic success and crosscultural interactions of domestic and international students. International Journal of Intercultural Relations, 38, 106119.

Grant, L., \& Kinman, G. (2012). Enhancing wellbeing in social work students: Building resilience in the next generation. Social Work Education, 31(5), 605-621.

Hamamura, T., \& Laird, P. G. (2014). The effect of perfectionism and acculturative stress on levels of depression experienced by East Asian international students. Journal of Multicultural Counseling and Development, 42(4), 205-217.

Hang, B.T.T., Kaur, A., \& Nur,A.H.B.(2017). A Self-Determination Theory based motivational model on intentions to drop out of vocational schools in Vietnam. Malaysian Journal of Learning and Instruction, 14(1), 1-21.

Hayes, A. F. (2009). Beyond Baron and Kenny: Statistical mediation analysis in the new millennium. Communication Monographs, 76(4), 408-420. 
Hayes, R. L., \& Lin, H. (1994). Coming to America: Developing social support systems for international students. Journal of Multicultural Counseling and Development, 22(1), 7-16.

Heine, S. J., \& Lehman, D. R. (2004). Move the body, change the self: Acculturative effects on the self-concept. Psychological Foundations of Culture, 8, 305-331.

Hendrickson, B., Rosen, D., \& Aune, R. K. (2011). An analysis of friendship networks, social connectedness, homesickness, and satisfaction levels of international students. International Journal of Intercultural Relations, 35(3), 281-295.

Holm-Hadulla, R. M., \& Koutsoukou-Argyraki, A. (2015). Mental health of students in a globalized world: Prevalence of complaints and disorders, methods and effectivity of counseling, structure of mental health services for students. Mental Health \& Prevention, 3(1-2), 1-4.

Katsiaficas, D., Suárez-Orozco, C., Sirin, S. R., \& Gupta, T. (2013). Mediators of the relationship between acculturative stress and internalization symptoms for immigrant origin youth. Cultural Diversity and Ethnic Minority Psychology, 19(1), 27-37.

Kaur, A., Noman, M., \& Nordin, H. (2017). Inclusive assessment for linguistically diverse learners in higher education. Assessment \& Evaluation in Higher Education, 42(5), 756-771.

Kim, J., \& Kim, H. (2013). The experience of acculturative stressrelated growth from immigrants' perspectives. International Journal of Qualitative Studies on Health and Well-Being, $8(1), 21355,1-11$.

Kim, J., Suh, W., \& Heo, J. (2014). Do Korean immigrant adolescents experience stress-related growth during stressful intergroup contact and acculturation? Journal of Humanistic Psychology, 54(1), 3-27.

Lazarus, R. S., \& Folkman, S. (1984). Coping and adaptation. The Handbook of Behavioral Medicine (pp. 282-325). New York: Guilford.

Lee, J.-S., Koeske, G. F., \& Sales, E. (2004). Social support buffering of acculturative stress: A study of mental health symptoms among Korean international students. International Journal of Intercultural Relations, 28(5), 399-414.

Lee, J., \& Ciftci, A. (2014). Asian international students' sociocultural adaptation: Influence of multicultural personality, assertiveness, academic self-efficacy, and social support. International Journal of Intercultural Relations, 38, 97-105. 
Li, A., \& Gasser, M. B. (2005). Predicting Asian international students' sociocultural adjustment: A test of two mediation models. International Journal of Intercultural Relations, 29(5), 561-576.

Li, Z., Heath, M. A., Jackson, A. P., Allen, G. E., Fischer, L., \& Chan, P. (2017). Acculturation experiences of Chinese international students who attend American universities. Professional Psychology: Research and Practice, 48(1), 11-21.

Liao, K. Y.-H., \& Wei, M. (2014). Academic stress and positive affect: Asian value and self-worth contingency as moderators among Chinese international students. Cultural Diversity and Ethnic Minority Psychology, 20(1), 107-115.

Lillyman, S., \& Bennett, C. (2014). Providing a positive learning experience for international students studying at UK universities: A literature review. Journal of Research in International Education, 13(1), 63-75.

Lowinger, R., He, Z., Lin, M., \& Chang, M. (2014). The impact of academic self-efficacy, acculturation difficulties, and language abilities on procrastination behavior in Chinese international students. College Student Journal, 48(1), 141-152.

Lu, S. H., Dear, B. F., Johnston, L., Wootton, B. M., \& Titov, N. (2014). An internet survey of emotional health, treatment seeking and barriers to accessing mental health treatment among Chinese-speaking international students in Australia. Counselling Psychology Quarterly, 27(1), 96-108.

Luo, N. (2017, August 16). Japan, Malaysia, Taiwan, and South Korea Remap Regional Student Flows. World Education News \& Reviews. Retrieved from https://wenr.wes.org/2017/08/ global-mobility-japan-malaysia-taiwan-and-south-koreaseek-to-shift-student-mobility-by-2025.

Martirosyan, N. M., Hwang, E., \& Wanjohi, R. (2015). Impact of English proficiency on academic performance of international students. Journal of International Students, 5(1), 60-71.

Meng, Q., Zhu, C., \& Cao, C. (2018). Chinese international students' social connectedness, social and academic adaptation: The mediating role of global competence. Higher Education, 75(1), 131-147.

Misra, R., Crist, M., \& Burant, C. J. (2003). Relationships among life stress, social support, academic stressors, and reactions to stressors of international students in the United States. International Journal of Stress Management, 10(2), 137-157. 
Misra, R., McKean, M., West, S., \& Russo, T. (2000). Academic stress of college students: Comparison of student and faculty perceptions. College Student Journal, 34(2), 236-246.

Myers-Walls, J. A., Frias, L. V, Kwon, K.-A., Ko, M.-J. M., \& Lu, T. (2011). Living life in two worlds: Acculturative stress among Asian international graduate student parents and spouses. Journal of Comparative Family Studies, 42(4), 455-478.

Naeeni, N. V., Zuria Mahmud, Amla Mohd Salleh, Salleh Amat, Maros, M., \& Morgan, M. M. (2015). Psycho-educational support groups and international university student adjustment in Malaysia: A qualitative inquiry. Australian Journal of Social Science, 1(1), 20-33.

Olivas, M.,\&Li,C.-S.(2006).Understanding stressors of international students in higher education: What college counselors and personnel need to know. Journal of Instructional Psychology, 33(3), 217-222.

Oppedal, B., Røysamb, E., \& Sam, D. L. (2004). The effect of acculturation and social support on change in mental health among young immigrants. International Journal of Behavioral Development, 28(6), 481-494.

Pan, J.-Y. (2015). Predictors of post-migration growth for Chinese international students in Australia. International Journal of Intercultural Relations, 47, 69-77.

Pogrebtsova,E.,Craig,J.,Chris,A.,O’shea,D.,\&González $\square$ Morales, M. G. (2018). Exploring daily affective changes in university students with a mindful positive reappraisal intervention: A daily diary randomized controlled trial. Stress and Health, 34(1), 46-58.

Popper, K. (2005). The logic of scientific discovery. London: Routledge

Poyrazli, S., \& Grahame, K. M. (2007). Barriers to adjustment: Needs of international students within a semi-urban campus community. Journal of Instructional Psychology, 34(1), 2846.

Poyrazli, S., \& Lopez, M. D. (2007). An exploratory study of perceived discrimination and homesickness: A comparison of international students and American students. Journal of Psychology: Interdisciplinary and Applied, 141(3), 263280. https://doi.org/10.3200/JRLP.141.3.263-280

Preacher, K. J., \& Hayes, A. F. (2004). SPSS and SAS procedures for estimating indirect effects in simple mediation models. Behavior Research Methods, Instruments, \& Computers, 36(4), 717-731. 
Quan, L., Zhen, R., Yao, B., \& Zhou, X. (2014). The effects of loneliness and coping style on academic adjustment among college freshmen. Social Behavior and Personality: An International Journal, 42(6), 969-977.

Ramsay, S., Barker, M., \& Jones, E. (1999). Academic adjustment and learning rocesses: a comparison of international and local students in first $\square$ year university. Higher Education Research \& Development, 18(1), 129-144.

Richardson, M., Abraham, C., \& Bond, R. (2012). Psychological correlates of university students' academic performance: A systematic review and meta-analysis. Psychological Bulletin, 138(2), 353-387.

Rienties, B., Beausaert, S., Grohnert, T., Niemantsverdriet, S., \& Kommers, P. (2012). Understanding academic performance of international students: the role of ethnicity, academic and social integration. Higher Education, 63(6), 685-700.

Robson, C. (2011). Real world research: A resource for users of social research methods in applied settings 3rd edition. West Sussex: John Wiley \& Sons.

Rodriguez, N., Mira, C. B., Myers, H. F., Morris, J. K., \& Cardoza, D. (2003). Family or friends: Who plays a greater supportive role for Latino college students? Cultural Diversity and Ethnic Minority Psychology, 9(3), 236-250.

Rui, J. R., \& Wang, H. (2015). Social network sites and international students' cross-cultural adaptation. Computers in Human Behavior, 49, 400-411.

Sam, D. L., Tetteh, D. K., \& Amponsah, B. (2015). Satisfaction with life and psychological symptoms among international students in Ghana and their correlates. International Journal of Intercultural Relations, 49, 156-167.

Sandhu, D. S., \& Asrabadi, B. R. (1994). Development of an acculturative stress scale for international students: Preliminary findings. Psychological Reports, 75(1), 435-448.

Sawir, E., Marginson, S., Deumert, A., Nyland, C., \& Ramia, G. (2008). Loneliness and international students: An Australian study. Journal of Studies in International Education, 12(2), 148-180.

Schneider,M.E.,\& Ward,D.J.(2003).The role of ethnicidentification and perceived social support in Latinos' adjustment to college. Hispanic Journal of Behavioral Sciences, 25(4), 539-554.

Sennett, J., Finchilescu, G., Gibson, K., \& Strauss, R. (2003). Adjustment of black students at a historically white South African university. Educational Psychology, 23(1), 107-116. 
Singh, J., Zain, A., \& Jamil, H. (2011). Establishment of Institutional Policies to Support the Internationalization Process: The Case of Malaysian Research Universities. Ijhssnet.Com, 1(8), 130 139.

Smith, R. A., \& Khawaja, N.G. (2011). A review of the acculturation experiences of international students. International Journal of Intercultural Relations, 35(6), 699-713.

StudyMalaysia. (2017, June 15). Becoming An International Student In Malaysia And Immigration Procedures. International Students. Retrieved from https://www.studymalaysia.com/ international/applying-entering-malaysia-to-study/becomingan-international-student-in-malaysia

Suárez-Orozco,C.,Onaga,M.,\& deLardemelle,C.(2010).Promoting academic engagement among immigrant adolescents through school-family-community collaboration. Professional School Counseling, 14(1), 15-26.

Sümer, S., Poyrazli, S., \& Grahame, K. (2008). Predictors of depression and anxiety among international students. Journal of Counseling \& Development, 86(4), 429-437.

Tabachnick, B. G., \& Fidell, L. S. (2007). Using multivariate statistics. Boston : Allyn \& Bacon/Pearson Education.

Thomas, F., \& Sumathi, G. N. (2016). Acculturative Stress and Social Support among the International Students: An Empirical Approach. Global Management Review, 10(3), 61-72.

Van Gorp, L., Boroş, S., Bracke, P., \& Stevens, P. A. J. (2017). An exploratory study into organizational repatriates' emotional support network. Cross Cultural \& Strategic Management, 24(4), 645-668.

Wan, R., Nordin, S. M., \& Razali, R. (2013). International students' cultural experiences: Exploring socio-cultural and academic adjustment in Malaysian Universities. Recent Advances in Modern Educational Technologies, 31-37.

Wang, Q., \& Hannes, K. (2014). Academic and socio-cultural adjustment among Asian international students in the Flemish community of Belgium: A photovoice project. International Journal of Intercultural Relations, 39, 66-81.

Wider, W., Mustapha, M., Halik, M., \& Bahari, F. (2017). Attachment as a predictor of university adjustment among freshmen: Evidence from a Malaysian public university. Malaysian Journal of Learning and Instruction, 14(1), 111-144.

Wilcox, P., Winn, S., \& Fyvie $\square$ Gauld, M. (2005). 'It was nothing to do with the university, it was just the people': The role of 
social support in the first year experience of higher education. Studies in Higher Education, 30(6), 707-722.

Yan, K. (2017). Chinese International Students in the United States: Adjustment Problems and Coping Behaviors. Chinese International Students' Stressors and Coping. Singapore: Springer.

Yeh,C.J.,\& Inose,M.(2003). International students'reported English fluency, social support satisfaction, and social connectedness as predictors of acculturative stress. Counselling Psychology Quarterly, 16(1), 15-28.

Zajacova, A., Lynch, S. M., \& Espenshade, T. J. (2005). Self-efficacy, stress, and academic success in college. Research in Higher Education, 46(6), 677-706.

Zhang, J., \& Goodson, P. (2011). Predictors of international students' psychosocial adjustment to life in the United States: A systematic review. International Journal of Intercultural Relations, 35(2), 139-162.

Zhou, Y., Jindal-Snape, D., Topping, K., \& Todman, J. (2008). Theoretical models of culture shock and adaptation in international students in higher education. Studies in Higher Education, 33(1), 63-75.

Zimet, G. D., Dahlem, N. W., Zimet, S. G., \& Farley, G. K. (1988). The multidimensional scale of perceived social support. Journal of Personality Assessment, 52(1), 30-41. 